\title{
Geomorphological inheritance for loess landform evolution in a severe soil erosion region of Loess Plateau of China based on digital elevation models
}

\author{
XIONG LiYang ${ }^{1}$, TANG GuoAn ${ }^{1 *}$, YUAN BaoYin ${ }^{2}$, LU ZhongChen ${ }^{3}$, \\ LI FaYuan ${ }^{1} \&$ ZHANG Lei ${ }^{1}$ \\ ${ }^{1}$ Key Laboratory of Virtual Geographic Environment, Ministry of Education, Nanjing Normal University, Nanjing 210023, China; \\ ${ }^{2}$ Institute of Geology and Geophysics, Chinese Academy of Sciences, Beijing 100029, China; \\ ${ }^{3}$ Research Center for Eco-Environmental Sciences, Chinese Academy of Sciences, Beijing 100085, China
}

Received February 18, 2013; accepted October 27, 2013; published online May 27, 2014

\begin{abstract}
The influence of pre-quaternary underlying terrain on the formation of loess landforms, i.e., the geomorphological inheritance issue, is a focus in studies of loess landforms. On the basis of multi-source information, we used GIS spatial analysis methods to construct a simulated digital elevation model of a pre-quaternary paleotopographic surface in a severe soil erosion area of the Loess Plateau. To reveal the spatial relationship between underlying paleotopography and modern terrain, an $X Y$ scatter diagram, hypsometric curve, gradient and concavity of terrain profiles are used in the experiments. The experiments show that the altitude, gradient and concavity results have significant linear positive correlation between both terrains, which shows a relatively strong landform inheritance relationship, particularly in the intact and complete loess deposit areas. Despite the current surface appearing somewhat changed from the original shape of the underlying terrain under different erosion forces, we reveal that the modern terrain generally smoothes the topographic relief of underlying terrain in the loess deposition process. Our results deepen understanding of the characteristics of geomorphological inheritance in the formation and evolution of loess landforms.
\end{abstract}

loess landform, landform inheritance, underlying paleotopography, digital elevation model

Citation: Xiong L Y, Tang G A, Yuan B Y, et al. 2014. Geomorphological inheritance for loess landform evolution in a severe soil erosion region of Loess Plateau of China based on digital elevation models. Science China: Earth Sciences, 57: 1944-1952, doi: 10.1007/s11430-014-4833-4

The Loess Plateau of China is known for its unique landforms, formed after more than two million years of loess deposition and sculpted by forces of water and wind erosion. The plateau has a complex and diverse landscape, with a specific spatial distribution pattern of the modern landforms. The loess landforms were formed and developed on the basis of inheritance of the underlying paleotopography, the morphology and distribution of which profoundly affect the combination and spatial distribution of the modern land-

*Corresponding author (email: tangguoan@njnu.edu.cn) forms. Hence, studying loess landform inheritance is critical toward understanding the formation mechanisms and development stages of the Loess Plateau and loess landforms. The paleotopography underlying loess refers to the original terrain prior to loess deposition of the Quaternary period. This study can play a fundamental role in revealing the geologic environment and evolutionary background of loess landforms by investigating the relationship between loess deposition and the paleotopography, calculating loess thickness and erosion amount, analyzing the effect of underlying terrain on loess landform development, and pre- 
dicting the evolution tendency of these landforms.

Earlier studies on loess landforms have investigated the relationship between loess deposition and underlying loess paleotopography through comparison of individual profiles with their morphology and formation history, of both the underlying paleotopographic surface and modern surface. Liu (1985) asserted that the morphology of modern landforms on the Loess Plateau possessed the properties of inheritance, i.e., the modern terrain inherits the complexity and diversity of the original pre-quaternary terrain. Beginning in the Quaternary period, winds from the northwest deposited airborne dust particles in the middle reaches of the Yellow River, which began to accumulate on the bedrock. This geologic process buried the eroded undulating hills and karst depressions during the Mesozoic and Cenozoic. Hence, the so-called formed loess terrain basically inherited or reflected morphological variations of the underlying paleotopography. Around the middle reaches of the Yellow River, different types of underlying paleotopography had a limited effect on the continuity of loess distribution. Current landforms, i.e., loess tablelands, ridges and hills, are closely related to morphology of the underlying paleotopographic surface. Although the process of loess deposition has smoothed the roughness of the underlying paleotopography, the modern terrain could still reflects the contours of the buried relief. Yuan et al. (2007), Liu et al. (2006) and Deng (2001) found that the morphology of underlying paleotopography prior to loess deposition determined the thickness of loess deposits and topographic relief of modern loess terrain. In the late Pliocene and early Quaternary, the types of loess paleotopographic surfaces on the plateau included bedrock mountain, bedrock hill, bedrock basin, settlement basin, rising basin, and valley terrace. The plateau is divided into seven paleotopographic districts, according to regional geomorphological differences. Corresponding to paleotopography of loess tableland, ridge and hill landforms, Guo (2002) and Sang et al. (2003) analyzed the structure of underlying rock in loess tableland in Luochuan and loess ridges in Yan'an-Ansai; they did not find significant inheritance in these loess landforms. Other scholars have adopted qualitative and semi-quantitative methods to describe erosion and developmental stages of the landforms (Chen, 1983; Li et al., 1990; Lu et al., 2003; Lu, 1991; Cheng et al., 2010; Li and Lu, 2010; Liu and Wu, 1993; Jing and Chen, 1983). It may be seen from the aforementioned studies that loess landform inheritance has been the subject of controversial viewpoints with respect to the process of loess evolution and deposition. However, these studies all used qualitative description or semi-quantitative analysis because of limitations of data sources and research methods, and they did not produce quantitative or regional characteristics of underlying paleotopography. In recent years, with rapid development of data acquisition techniques and more mature digital terrain analysis methods, new opportunities have arisen for exploring quantitative methods and mechanisms of landform evolution (Paik, 2012; Perron et al., 2009; Kyungrock, 2011; Bowman et al., 2010). However, it is rare to encounter progress regarding quantitative analysis and landform inheritance of loess landform evolution.

In the current work, based on geologic and loess thickness maps, high-definition remote sensing images and high-accuracy digital elevation models (DEMs), a DEM of the paleotopographic surface was constructed through intensive sampling of outcropping paleotopographic points in a severe soil erosion area of the Loess Plateau. Through comparative analyses with altitude and multiple profiles of topographic relief features of the paleotopographic and modern surfaces, we quantitatively reveal the relationship between the two terrains.

\section{Materials and methods}

\subsection{Materials}

(1) DEM: SRTM (Shuttle Radar Topography Mission) with resolution $90 \mathrm{~m}$ was chosen as the basic DEM data source, because of its appropriate height precision and applicability to geomorphological mapping at macroscale (Zhan, 2008).

(2) Geologic map: An information source for outcropping points of bedrock in the loess area with scale 1:200000, composed by the Institute of Geology and Geophysics of the Chinese Academy of Sciences.

(3) Remote sensing imagery was applied to positional correction within bedrock outcropping point mapping.

(4) Loess thickness distribution map (Liu, 1985): Tertiary red clay and early paleotopographic regions are designated on the geologic map. Hence, thickness distribution data of loess were used to provide further control for terrain simulation of the Tertiary surface.

\subsection{Methods}

\subsubsection{Data preprocessing}

The SRTM gives global subdivision elevation data with approximately $90 \mathrm{~m}$ cell size, and there is a systematic deviation of resolution for each dataset. To unify the DEM data resolution, all data were resampled; the resulting data had $100 \mathrm{~m}$ cell size and covered all the experimental sites.

\subsubsection{Height detection of outcropping bedrock strata points}

In this experiment, coordinates and elevations for the outcropping bedrock points were collected based on the geologic maps, in which definite geologic age and rock type for those points were assigned. The method was implemented via the following steps. First, the outcropping points of bedrock in channels or valleys were determined based on 
the geologic maps. Second, image-based positional correction of the bedrock points was done. Finally, an overall outcropping bedrock strata point dataset (Figure 1) was constructed. Because the limited sample points could not provide an overall surface trend for the Tertiary red clay strata, actual measurement data and loess thickness contour maps (Liu, 1985) were used to assist construction of a loess paleotopographic surface model. All sampling points are shown in Figure 1. The major research area is the severe soil erosion zone (Upper and Middle Yellow River Bureau, 2012) on the Loess Plateau, where there is a high density of outcropping bedrock strata points.

\section{Results and analysis}

\subsection{Modeling of paleotopography underlying loess}

A total of 1739 sampling points were randomly distributed in the experimental area. To improve accuracy of the simulation result, more high-quality sampling was done near the Yellow River and its secondary tributaries. For rocky mountainous regions ( $\mathrm{Li}$ and $\mathrm{Lu}, 2010$ ) inside the experimental area, such as Ziwu Mountain, Huanglong Mountain and others, their DEM data were directly input to the elevation model of the underlying loess paleotopography. Finally, based on the outcropping bedrock strata points, the DEM of the underlying loess paleotopography in the area was constructed via interpolation. Through comparison of all interpolation methods (Mitas and Mitasova, 1988; Sibson, 1981; Watson and Philip, 1985; McBratney and Webster, 1986;
Oliver, 1990; Press et al., 1988; Royle et al., 1981), the spline method is considered the most suitable for our application, because of its high accuracy (RMSE $36.5 \mathrm{~m}$; relative error less than 12\%) and relatively small variation. Eighty percent of the sampling points were prepared for interpolation; the remaining $20 \%$ were used for accuracy detection. The simulation result of the underlying loess paleotopography is shown in Figure 2(b).

\subsection{Analysis of loess landform inheritance}

Both qualitative and quantitative analysis methods were used to investigate the landform inheritance relationship between the modern loess surface and paleotopographic surface underlying loess. Macroscopic characteristics of the study area are regarded as the basis for the comprehensive identity and systematic evaluation of loess landforms. The core work is to obtain appropriate indicators that reflect the features of landform inheritance. Through comparative analysis of existing indicators, a hypsometric curve ( $\mathrm{Lu}$ et al., 2003) reflecting geomorphologic developmental stages and an $X Y$ scatter diagram (Liu et al., 2008; Cheng and Xiong, 2011) of elevation points were selected as analysis indicators for the macroscale. Gradient and parabolic concavity (Li et al., 1990; Lu et al., 2003) of several fixed terrain profiles were used as indicators for the microscale.

\subsubsection{XY scatter diagram}

In an XY scatter diagram (Liu et al., 2008), the X-axis represents elevation of the paleotopography underlying loess,

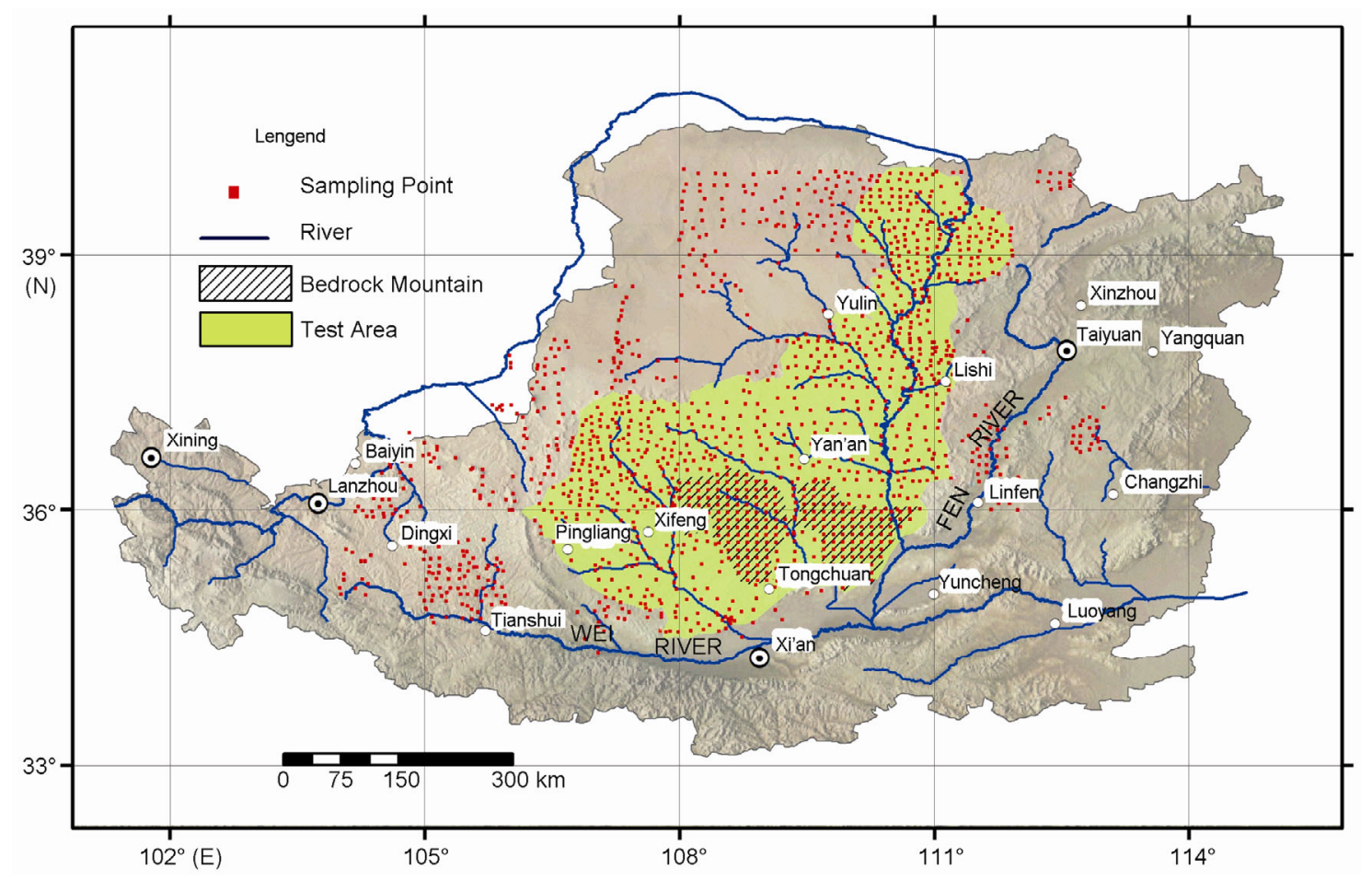

Figure 1 Test area and distribution of sampling points. 

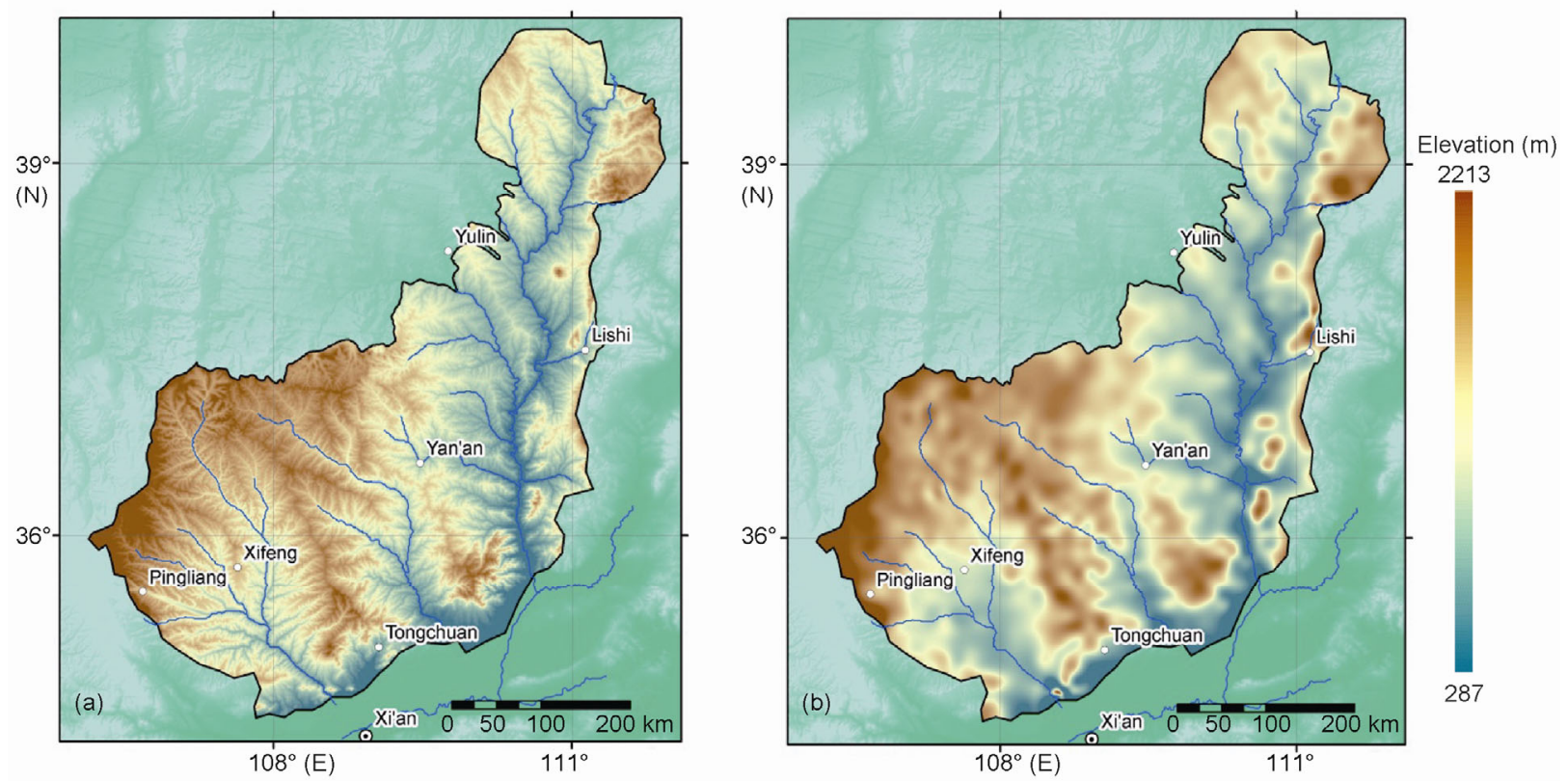

Figure 2 Illustrations of modern DEM (a) and simulated underlying paleotopographic DEM (b).

and the $y$-axis is elevation of the modern terrain. Correlation between these two variables on the diagram is shown by the distribution of elevation point pairs. This correlation can be expressed as $Y=a+b \times X$. If $b$ is equal to 1 , topographic relief of the underlying paleotopography and modern terrain conform (Figure 3-p2). In contrast, if $b$ is greater than 1, topographic relief of the modern terrain is more rugged than that of the underlying terrain (Figure 3-p1). However, if $b$ is less than 1 , topographic relief of the modern terrain is gentle relative to that of the underlying one (Figure 3-p3).

According to the $X Y$ scatter diagram shown in Figure 4, 1.57 million elevation point pairs show a significant linear relationship. Their equation of fit is $f(X)=141.7+0.94 \times X$ (where $b$ is less than 1) and the correlation coefficient is 0.90 (as in Figure 3-p3). The results show that the modern terrain clearly inherits the underlying paleotopography, but smoothes the topographic relief of that paleotopography during the process of loess deposition.

To reveal the spatial difference of loess landform inheritance, correlation between the modern and underlying terrain was calculated for different loess landform divisions (Upper and Middle Yellow River Bureau, 2012) (Figure 5). Table 1 shows parameters obtained based on $Y=a+b \times X$, which reveals a significant difference in loess landform in-

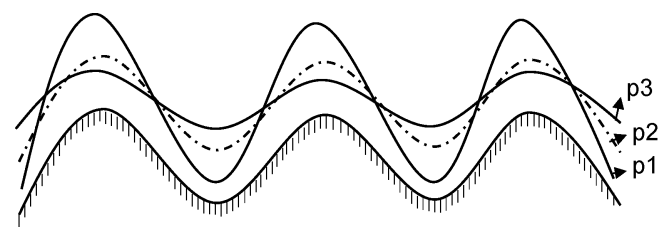

Figure 3 Different deposition relationships between modern surface and underlying paleotopographic surface.
Table $1 \quad X Y$ scatter diagram parameters for different landform divisions

\begin{tabular}{ccccc}
\hline Landform divisions & Slope $(b)$ & $R^{2}$ & RMSE & Intercept $(a)$ \\
\hline Sub-area I of loess hill-gully (Q1) & 0.91 & 0.89 & 58 & 169.3 \\
Sub-area II of loess hill-gully (Q2) & 0.97 & 0.95 & 65 & 112.2 \\
Sub-area V of loess hill-gully (Q5) & 0.67 & 0.45 & 67 & 599.7 \\
Loess tableland area (Y1) & 0.86 & 0.83 & 76 & 202.2 \\
Loess tableland area (Y2) & 0.92 & 0.80 & 100 & 196.6 \\
Entire test area & 0.95 & 0.90 & 77 & 141.7 \\
\hline
\end{tabular}

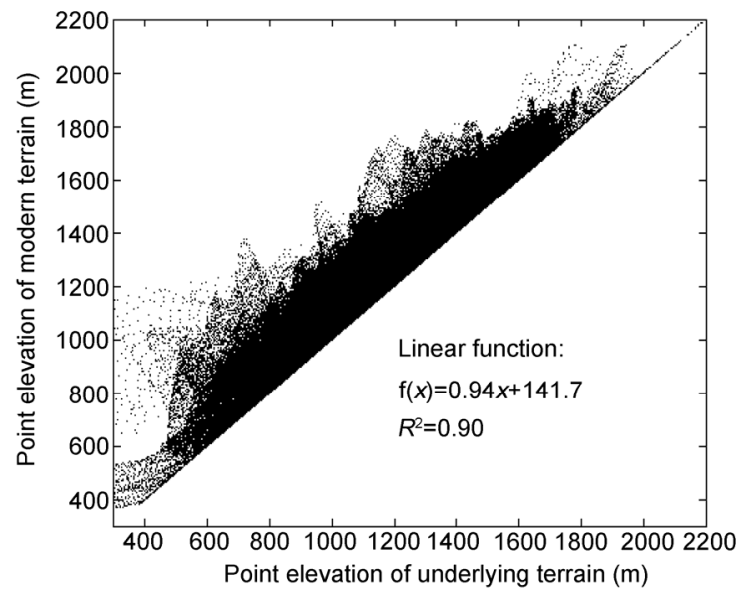

Figure $4 X Y$ scatter diagram.

heritance by district. The inheritance of sub-area II of loess hill-gully is most obvious. From sub-area I of loess hill-gully to loess tableland area to sub-area $\mathrm{V}$ of loess hill-gully, the significance gradually decreases. All these demonstrate that the process of loess deposition reduces the topographic relief of the underlying paleotopography. 


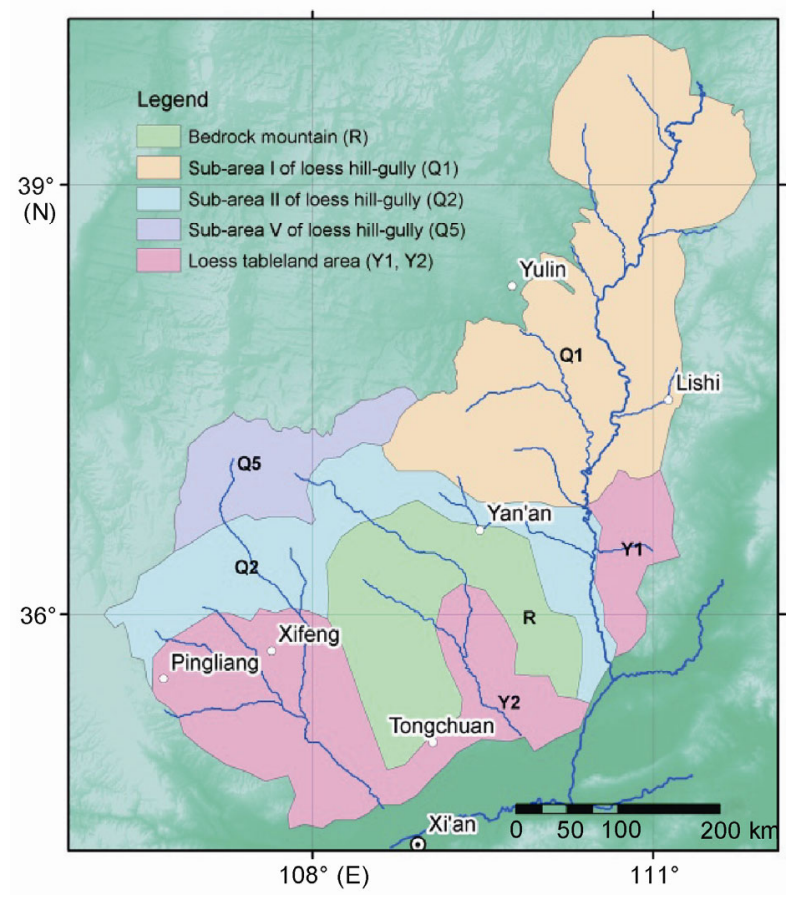

Figure 5 Landform divisions in the test area.

\subsubsection{Hypsometric curve}

The hypsometric integral curve is a geographic model that reflects the landform development stage. The corresponding hypsometric curve is defined by the area of the transverse section and relative relief to the water outlet. Based on interaction of internal and external forces over time, the curve can depict landform evolution. The hypsometric integral value can indicate landform erodibility ( $\mathrm{Li}$ et al., 1990). The hypsometric curve divides its enveloping rectangle into two parts. The integral value refers to the area of the bottom portion divided by that of the entire rectangle. The calculation is as follows.

$$
E_{i}=\frac{\int_{0}^{H} a \mathrm{~d} h}{H A}=\int_{0}^{1} x \mathrm{~d} y,
$$

where $H$ is the watershed gradient, $A$ its area, $h$ its relative height, and $a$ the area of the transverse section.

Based on eq. (1), hypsometric integral values for both modern terrain and underlying paleotopography can be derived. The calculated results are 0.43 for the former and 0.47 for the latter. Both values illustrate that the areas are in the metaphase of the erosion process, according to $\mathrm{Li}$ et al. (1990). Figure 6 shows that hypsometric curves for the modern terrain are in the upper portion and parallel to the bottom one, with similar shapes and trends. This reveals clear inheritance of loess landform from the underlying paleotopography.

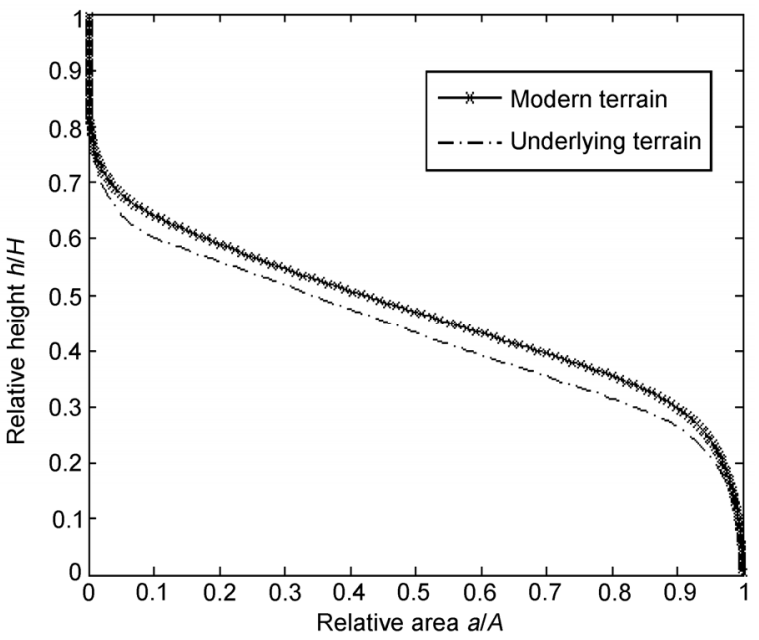

Figure 6 Hypsometric curve.

\subsubsection{Terrain profiles}

Using a group of terrain profiles extracted from DEMs of the underlying and modern terrains, the spatial relationship and distribution pattern between them can be clearly illustrated. As shown in Figure 7, twelve pairs of terrain profiles were extracted in four directions. These are lines a1, a2 and a3 from east to west, b1, b2 and b3 from south to north, c1, c2 and c3 from southeast to northwest, and d1, d2 and d3 from northeast to southwest. Figure 8 shows altitude graphs of these terrain profiles. Referring to locations of rocky hill areas and rivers in Figure 1, profiles a1 and d3 are across

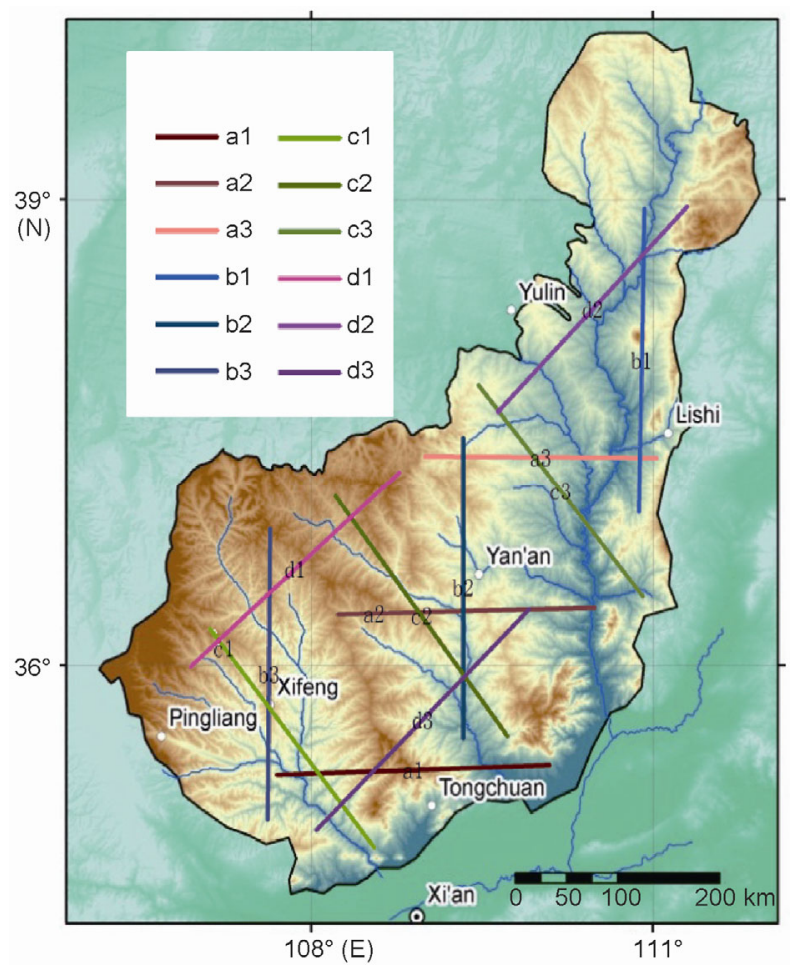

Figure 7 Terrain profiles. 

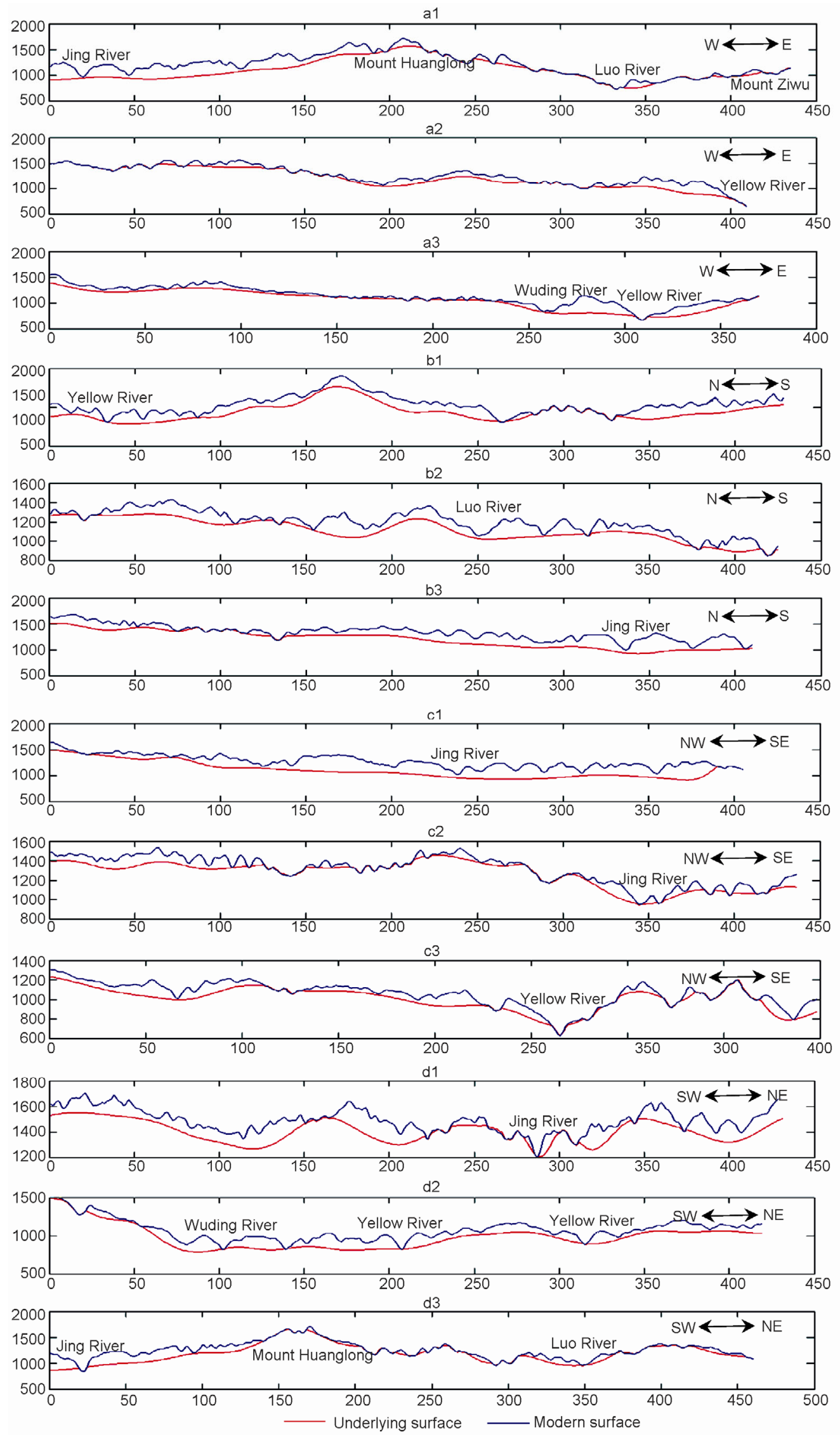

Figure 8 Terrain profiles of underlying surface and modern surface (unit: $\mathrm{m}$ ). 
some rocky hill areas, i.e., Mount Huanglong and Mount Ziwu. Profiles a2, a3, b1, c3 and d2 are across the Yellow River. Other lines cross tributaries of the Yellow River, such as the Jing River.

The gradient and concavity of the terrain profiles are indicators that describe profile features quantitatively. The least squares method was applied to calculation of these two factors, with more satisfactory results. According to results in Zhan (2008), the SRTM DEM with $100 \mathrm{~m}$ cell size for the Loess Plateau has approximately ten meters RMSE for elevation, which would not affect accuracy in the calculation of the two factors. With comparison of each profile pair, we can further portray the loess landform inheritance.

The least squares method was used to calculate the profile gradients (Lu et al., 2003). It uses the following:

$$
J=\frac{n \Sigma x y-\Sigma x \Sigma y}{n \Sigma x^{2}-(\Sigma x)^{2}}
$$

where $J$ denotes the profile gradient, $n$ is the profile number, $x$ is the constant distance between each profile pair, and $y$ is the profile elevation.

As demonstrated by Lu et al. (2003), the profile concavity, corresponding to the exponent $n$ of the independent variable in the parabola curve, describes the degree of concavity in the profile. In eq. (3), $n$ is the morphological factor for the profile function:

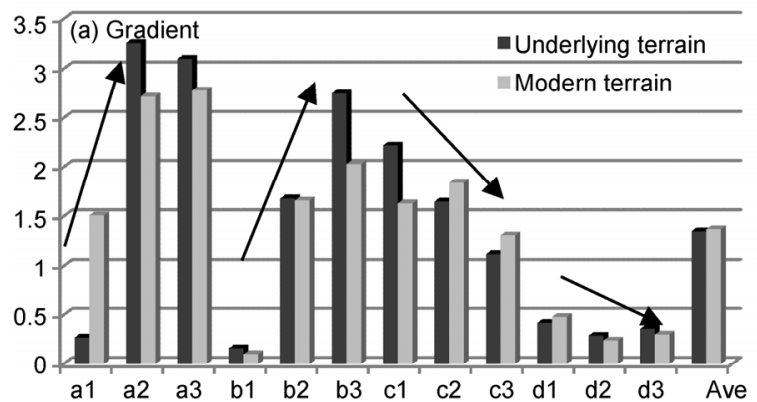

$$
h=H\left(\frac{l}{L}\right)^{n},
$$

where $h$ is elevation of any point in the profile, $H$ is its maximum elevation, $l$ is the distance from any point to the run off outlet point, and $L$ is horizontal length of the profile.

In the terrain profiles of Figure 8, the profile line divides the entire rectangle area into two halves (upper and lower portions) by an envelope rectangle. Then, $n$ is calculated by dividing the upper portions by the lower ones. If $n$ is larger than 1 , the profile has a concave feature, while a convex feature corresponds to a value smaller than 1 . If $n$ equals 1 , the profile is linear. We assess the similarity or inheritance of the loess landform from different $n$ values in various evolutionary stages of test areas.

Table 2 shows the gradient and concavity of terrain profiles in the two different cases. Figure 9 indicates that both the underlying terrain and the modern terrain have approximately similar distributions, showing strong inheritance in morphology. Figure 9(a) shows that the gradient of both terrain profiles gradually increase from east to west and south to north, with slow decreases from northwest to southeast and southwest to northeast. Figure 9(b) illustrates that concavity of both terrain profiles had similar spatial variations, i.e., initially decreasing and then increasing from east to west, south to north, and southwest to northeast; this variation was reversed from northwest to southeast.

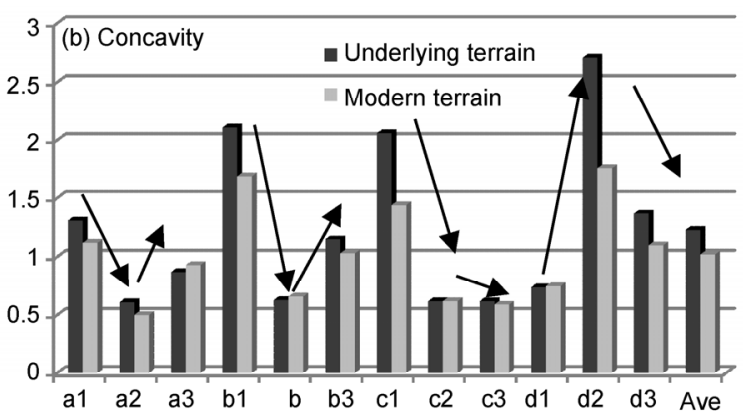

Figure 9 Illustrations of gradient and concavity for different terrain profiles.

\begin{tabular}{|c|c|c|c|c|c|c|c|c|c|c|c|c|c|c|}
\hline \multirow{2}{*}{\multicolumn{2}{|c|}{ Type }} & \multicolumn{12}{|c|}{ Profiles } & \multirow{2}{*}{ Average } \\
\hline & & a1 & a2 & a3 & b1 & b2 & b3 & $\mathrm{c} 1$ & c2 & c3 & $\mathrm{d} 1$ & $\mathrm{~d} 2$ & $\mathrm{~d} 3$ & \\
\hline \multirow{2}{*}{ Gradient } & $\begin{array}{c}\text { Underlying } \\
\text { terrain }\end{array}$ & -0.27 & -3.26 & -3.1 & -0.16 & -1.68 & -2.75 & -2.22 & -1.65 & -1.12 & -0.42 & -0.29 & -0.36 & -1.35 \\
\hline & Modern terrain & -1.51 & -2.72 & -2.78 & -0.1 & -1.66 & -2.03 & -1.63 & -1.84 & -1.31 & -0.48 & -0.24 & -0.3 & -1.37 \\
\hline \multirow{2}{*}{\multicolumn{2}{|c|}{ Type }} & \multicolumn{12}{|c|}{ Profiles } & \multirow{2}{*}{ Average } \\
\hline & & a1 & a2 & a3 & b1 & b2 & b3 & $\mathrm{c} 1$ & c2 & c3 & d1 & $\mathrm{d} 2$ & d3 & \\
\hline \multirow[t]{2}{*}{ Concavity } & $\begin{array}{l}\text { Underlying } \\
\text { terrain }\end{array}$ & 1.31 & 0.61 & 0.87 & 2.11 & 0.63 & 1.15 & 2.06 & 0.62 & 0.62 & 0.74 & 2.71 & 1.37 & 1.23 \\
\hline & Modern terrain & 1.12 & 0.5 & 0.93 & 1.69 & 0.66 & 1.03 & 1.44 & 0.62 & 0.59 & 0.75 & 1.76 & 1.1 & 1.02 \\
\hline
\end{tabular}

Table 2 Gradient and concavity of different profiles 

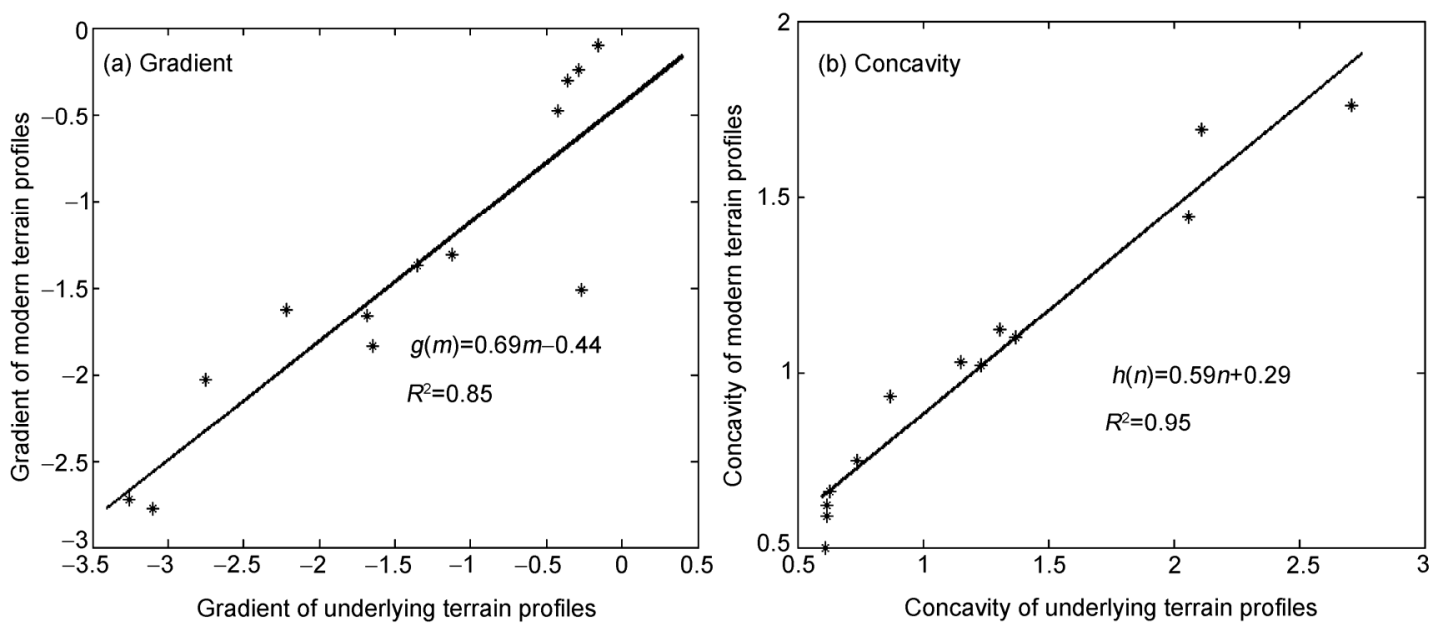

Figure 10 Linear correlations of modern terrain profiles and underlying terrain profiles.

Table 2 indicates that gradient and concavity values of the terrain profiles were very similar. Their relationship was investigated via linear correlation, with results shown in Figure 10 and eqs. (4) and (5). Gradient is expressed by eq. (4) and concavity by eq. (5):

$$
\begin{array}{ll}
g(m)=0.69 m-0.44, & \left(R^{2}=0.85\right), \\
h(n)=0.59 n+0.29, & \left(R^{2}=0.95\right) .
\end{array}
$$

$R^{2}$ values of both equations confirm the strong inheritance of the modern terrain from the underlying paleotopography.

\section{Conclusions}

(1) The comparative analysis of paleotopography underlying loess and modern terrain was useful for revealing the geomorphological inheritance of loess landforms. The proposed analysis methods and indexes, i.e., $X Y$ scatter diagram, hypsometric curve, gradient and concavity of profiles, can perform well in quantitative description of the geomorphological inheritance of loess landforms. This approach is also expected to be applied in geomorphological inheritance research of loess landforms at other spatial scales.

(2) All indicators show a significant landform inheritance relationship between modern terrain and underlying paleotopography. The former reduces the topographic relief of the original underlying paleotopography during the loess deposition process. The landform division statistical results show great spatial differences of geomorphological inheritance characteristics across different loess landform types. The significance of inheritance characteristics declines from the sub-area II of loess hill-gully to sub-area I of loess hill-gully to loess tableland area to sub-area $\mathrm{V}$ of loess hill-gully, and all divisions of modern terrain smooth topographic relief of the underlying paleotopography. The hypsometric integral result indicates that the hypsometric curve of modern terrain is higher and parallel to the underlying one, with extremely similar shapes and trends. This demonstrates strong inheritance of the underlying paleotopography by loess landforms. The terrain profile results show that despite a moderate topographic relief of underlying terrain, it still regulates the modern terrain to some extent.

(3) The simulation result of loess paleotopography applies only on a macro level, because of limited sampling methods and density. Development of modern geophysical techniques would provide better opportunities for future study of loess geomorphological inheritance at other spatial scales. DEM construction of Malan, Lishi and Wucheng loess strata should accomplished, which would deepen understanding of loess landform genesis and development mechanisms.

This research was supported by the National Natural Science Foundation of China (Grant Nos. 40930531, 41171320), the National High Technology Research and Development Program of China (Grant No. 2011AA120303), and Open Foundation of State Key Laboratory of Resources and Environmental Information System (Grant No. 2010KF0002SA). The authors express great thanks to everyone who helped in writing this article.

Bowman D, Svoray T, Devora S, et al. 2010. Extreme rates of channel incision and shape evolution in response to a continuous, rapid base-level fall, the Dead Sea, Israel. Geomorphology, 114: 227-237

Chen Y Z. 1983. A preliminary analysis of the processes of sediment yield in small catchment on the Loess Plateau (in Chinese). Geogr Res, 2: 35-47

Cheng H Z, Xiong L H. 2011. A local topography-based variable outflow width method for determining multiple flow directions of DEM (in Chinese). Sci Geogr Sin, 31: 218-225

Cheng Y P, Shi J S, Yang Z J, et al. 2010. Control of ancient landform on rock-soil erosion in loess area (in Chinese). Arid Land Geogr, 33: 334-339

Deng C L, Yuan B Y. 2001. Processes of gully erosion and accumulation in the central loess plateau of China since the last interglacial (in Chinese). Acta Geogr Sin, 56: 92-98

Guo L Y. 2002. The relationship between the loess landform and its bedrock type and the impact of the structure on erosion in Shaanbei (in 
Chinese). Doctoral Dissertation. Xi'an: Shanxi Normal Univ. 1-71

He Y, Jia T F, Li R Q. 1999. Development of gullies and evaluation on their stability in the loess hill region (in Chinese). Arid Land Geogr, 22: 64-70

Jing K, Chen Y Z. 1983. Preliminary study of the erosion environment and rates on the Loess Plateau (in Chinese). Geogr Res, 2: 1-11

Kyungrock P. 2011. Optimization approach for 4-D natural landscape evolution. IEEE Trans Evol Comput, 15: 684-691

Li L P, Lu H Y. 2010. A preliminarily quantitative estimation of the sedimentation and erosion rates of loess deposits in Chinese Loess Plateau over the past $250 \mathrm{ka}$ (in Chinese). Acta Geogr Sin, 1: 37-52

Li Q, Lu Z C, Yuan B Y. 1990. Quantitative study of the stage of geomorphological evolution (in Chinese). Acta Geogr Sin, 45: 110-120

Liu D S. 1985. Loess and Environment (in Chinese). Beijing: Science Press. 481

Liu B Z, Wu F Q. 1993. A study on gully and valley erosion and its development in Loess Yuan area. J Soil Water Conser, 7: 33-39

Liu J F, Guo Z T, Qiao Y S, et al. 2006. Eolian origin of the Miocene loess-soil sequence at Qin'an, China: Evidence of quartz morphology and quartz grain-size. Chin Sci Bull, 51: 117-120

Liu X J, Jin B, Wang Y F. 2008. Similarity analysis of flow route algorithms for extracting drainage network from grid-based terrain model (in Chinese). Geogr Res, 27: 1347-1357

Lu Z C. 1991. Basin Morphologic System (in Chinese). Dalian: Dalian Press. 356

Lu Z C, Zhou J X, Chen H. 2003. River bed longitudinal profile morphology of the lower Yellow River and its implication in physiography (in Chinese). Geogr Res, 22: 30-38

McBratney A B, Webster R. 1986. Choosing functions for semivariograms of soil properties and fitting them to sampling estimates. J Soil Sci, 37: 617-639

Mitas L, Mitasova H. 1988. General variational approach to the interpolation problem. Comput Math Appl, 12: 983-992
Oliver M A. 1990. Kriging: A method of interpolation for geographical information systems. Int J Geogr Inf Sci, 4: 313-332

Paik K. 2012. Simulation of landscape evolution using a global flow path search method. Environ Model Software, 33: 35-47

Perron J T, Kirchner J W, William E D. 2009. Formation of evenly spaced ridges and valleys. Nature, 460: 502-505

Press W H, Teukolsky S A, Vetterling W T, et al. 1992. Numerical Recipes in C: The Art of Scientific Computing. New York: Cambridge Univ Press. 129-162

Royle A G, Clausen F L, Frederiksen P. 1981. Practical universal kriging and automatic contouring. Geoprocessing, 1: 377-394

Sang G S, Chen X, Chen X N, et al. 2007. Formation model and geomorphic evolution of loess hilly landforms (in Chinese). Arid Land Geogr, 30: 375-380

Sang G S, Gan Z M, Yue D P. 2003. Gully development and soil erosion in the loess Yuan region since Yuan dynasty (in Chinese). Arid Land Geogr, 26: 355-360

Sibson R. 1981. A Brief Description of Natural Neighbor Interpolation. New York: John Wiley \& Sons. 21-36

Upper and Middle Yellow River Bureau. 2012. Atlas of Soil and Water Conservation in the Yellow River Basin (in Chinese). Beijing: Seismological Press. 195

Watson D F, Philip G M. 1985. A refinement of inverse distance weighted interpolation. Geoprocessing, 2: 315-327

Yuan B Y, Guo Z T, Hao Q Z, et al. 2007. Cenozoic evolution of geomorphic and sedimentary environments in the Tianshui-Qin'an regions (in Chinese). Quat Sci, 27: 161-171

Yuan B Y, Ba T, Cui Q X, et al. 1987. The relationship between gully development and climatic changes in the Loess Yuan region: Examples from Luochuan, Shaanxi province (in Chinese). Acta Geogr Sin, 42: 328-227

Zhan L. 2008. Evaluation of SRTM DEMs' accuracy and investigation on its applicability-A case study in Shaanxi Province (in Chinese). Master's thesis. Nanjing: Nanjing Normal Univ. 1-87 